\title{
Alcoholic liver disease is a strong predictor of colorectal polyps in liver transplant recipients
}

\section{(ㄷ)(1) $\odot$}

\author{
Authors \\ Institutions \\ 1 Service de gastroentérologie et d'hépatologie, Hôpital \\ St-Luc, Centre Hospitalier de l'Université de Montréal, \\ Montréal, QC, Canada \\ 2 Centre de Recherche, Centre Hospitalier de l'Université \\ de Montréal, Montréal, QC, Canada
}

Ann T. Ma ${ }^{1}$, Amélie Therrien¹,2, Jeanne-Marie Giard ${ }^{1,2}$, Daniel von Renteln ${ }^{1,2}$, Mickael Bouin ${ }^{1,2}$

submitted 29.9.2016

accepted after revision $\quad 2.5 .2017$

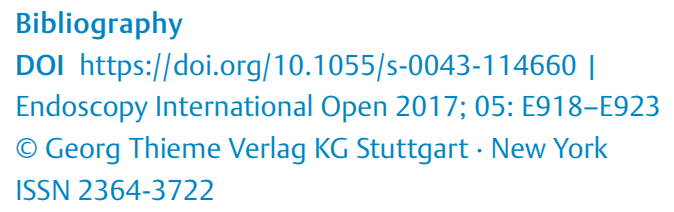

Corresponding author

Ann T. Ma, MD, Hôpital St-Luc, Centre Hospitalier de I'Université de Montréal, 1058 Rue Saint-Denis, Montréal, QC, Canada, H2X 3J4

Fax: +1-514-412-7372

ann.thu.ma@umontreal.ca

\section{ABSTRACT}

Background and aims Colorectal cancer (CRC) is associated with a significantly reduced survival rate in transplant recipients. The prevalence and risk factors of CRC and of colorectal polyps after orthotopic liver transplant (OLT) remain unclear. The study aim was to determine the prevalence of colorectal polyps in OLT recipients. A secondary objective was to explore possible risk factors of polyps. Patients and materials This was a retrospective single center study of all OLT recipients transplanted between 2007 and 2009. All patients who underwent a colonoscopy $5 \pm 5$ years after OLT were included. The outcome was colorectal polyps, as identified on colonoscopy. A logistic regression model was performed to identify potential predictors of polyps.

Results Of 164 OLT recipients, 80 were included in this study. Polyps were diagnosed in $37 \%$ of patients before transplant and in $33 \%$ afterwards. With regard to posttransplant lesions, $22 \%$ were advanced adenomas or cancerous. In the regression analysis, the odds of post-transplant polyps were 11 times higher in patients with alcoholic liver disease (OR 11.3, $95 \% \mathrm{Cl} 3.2-39.4 ; P<0.001)$.

Conclusion Patients with end-stage liver disease may be at high risk of colorectal polyps before and after liver transplant, and screening should be continued in both contexts. Those with alcoholic liver disease are particularly at risk for post-OLT polyps and may benefit from more intensive screening.

\section{Introduction}

After orthotopic liver transplantation (OLT), patients require immunosuppressive medication, which puts them at risk for development of post-transplant neoplasm and increased mortality [1]. Between $2.5 \%$ and $25 \%$ of patients develop cancer within 1.5 to 5 years after transplant [2-4]. Skin cancer and lymphoproliferative disorders represent the majority of postOLT cancers [5]. Nevertheless, colorectal cancer (CRC), though less prevalent, is associated with a markedly reduced survival in post-transplant patients ( $30 \%$ at 5 years compared to $63 \%$ in the general, non-transplant population) [6]. In addition, CRC may appear at an earlier age in solid organ recipients, with two studies describing a median of 54 and of 59 years at diagnosis, compared to 72 years in the general, non-transplant, population in the United States $[6,7]$.

The majority of colorectal adenocarcinomas develop out of precancerous lesions, so-called colon adenomas [8]. The prevalence of colorectal adenomas in OLT candidates varies from $21 \%$ to $23 \%$ in some studies $[9,10]$, and age appropriate pretransplant colonoscopy screening is recommended $[11,12]$. The presence of primary sclerosing cholangitis (PSC) and inflammatory bowel disease (IBD) increases the risk of developing CRC post-transplant [13], and current guidelines recommend annual screening in this population [11,12]. However, no specific guidelines exist on screening non-PSC patients 
post-transplant, although they have 1.8 times more risk of developing CRC than age-matched controls [14]. Predictors of post-transplant CRC, which could aid in developing targeted screening recommendations, have not yet been studied.

The main objective of our study was to determine the prevalence of colorectal polyps and CRC in liver transplant recipients. A secondary objective was to investigate whether their presence is associated with age, sex, smoking, immunosuppressive agent, liver disease, and pre- and post-transplant colonoscopy characteristics.

\section{Methods}

This was a retrospective descriptive study of liver transplant recipients at Hôpital Saint-Luc, Centre Hospitalier de l'Université de Montréal (CHUM), Montreal, Canada.

\section{Study population}

Patients $\geq 18$ years who were transplanted between 1 January 2007 and 31 December 2009 and who underwent a complete colonoscopy $5 \pm 5$ years post-transplant were included. At our tertiary center, a systematic colonoscopy is part of the pre-OLT work-up, and a colonoscopy about 5 years post-OLT has been implemented as part of a surveillance strategy post-OLT. This program is mostly addressed to patients $\geq 50$ years, but is also carried out in patients $<50$ years with CRC risk factors, which include previous advanced adenoma, PSC and IBD, and personal or familial history of CRC. Patients with total proctocolectomy or who have not undergone at least one post-transplant colonoscopy were excluded from this study. In our study, $88 \%$ of colonoscopies were done by gastroenterologists (the remainder were performed by general surgeons, internists or the information was not available). In total, $71 \%$ of colonoscopies were done at our center by endoscopists $(n=6)$ with over 10 years of experience. Our center is a provincial colorectal cancer screening center, but the data on adenoma detection rate (ADR) is not available for all gastroenterologists. In addition, we do not have information on the ADR and experience of gastroenterologists outside our center. The study has been approved by the Research Ethics Committee of the CHUM, which complies with the Declaration of Helsinki.

\section{Data collection and definitions}

For data collection, charts up to May 2016 were reviewed for all liver transplant recipients. All associated colonoscopy reports were reviewed for the presence of colorectal polyps, the primary end point being at least 1 polyp. When more than one post-transplant colonoscopy was performed, only the earliest colonoscopy with a polyp or the latest one if no polyp was identified was used for assessment. The indication for colonoscopy was classified as screening, surveillance, or diagnostic [15]. The label "screening" was used for colonoscopies in asymptomatic patients with no CRC risk factors or only a positive family history for CRC. The term "surveillance" was used for colonoscopies in asymptomatic patients with a history of colonic disease, such as previous colorectal adenomas, previous CRC and IBD. "Diagnostic" colonoscopies were performed in patients who had been referred for symptoms or for an abnormal biochemical or medical imaging result. The endoscopies whose indication was not apparent were labeled as screening colonoscopies. Polyps were defined as being proximal to the splenic flexure when specified as such or if it was found beyond $50 \mathrm{~cm}$ of straightened colonoscope [16]. Patients with more than one lesion were categorized to the most advanced lesion. Additional medical data were documented: ethnicity, smoking status, liver disease before transplant, and CRC risk factors. Advanced adenoma was defined as polyp $\geq 1 \mathrm{~cm}$, villous or tubulovillous histology, or high grade dysplasia. Cancerous lesions comprised colorectal adenocarcinoma. Two patient groups were formed: Group PrePost comprised patients having undergone both preand post-transplant colonoscopies, and Group Post included patients who only had a post-transplant colonoscopy.

\section{Statistical analysis}

Patient characteristics have been summarized as percentages or median with interquartile range [IQR] when appropriate. Due to the sample size and the non-normal distribution of the data, the median age at transplant and at post-transplant colonoscopy was compared using the Mann-Whitney $U$ test. Groups PrePost and Post were compared with regard to post-OLT polyp prevalence, proportion of $\geq 1 \mathrm{~cm}$ polyps, and proportion of advanced lesions using the Fisher's Exact test. This test was also applied to compare patients with and without post-transplant polyps with regard to: sex, age ( $\geq 60$ years), current or past smoking, alcoholic liver disease, non-alcoholic fatty liver disease, IBD/PSC, calcineurin inhibitor use, pre-transplant colonoscopy, pre-transplant polyps, timing of colonoscopy $(\geq 5$ years post-OLT), and colonoscopy indication. Using the previous variables, a stepwise logistic regression analysis, with conditional forward selection, was performed to identify predictors of post-transplant polyps. For the analyses, surveillance and diagnostic colonoscopies were grouped owing to the small sample size and because of a reported higher prevalence of polyps compared to screening colonoscopy $[17,18]$. Statistical analyses were done using $R$ (version 2.15.0, 2012) and IBM SPSS Statistics 22 software (SPSS Inc, Chicago, Illinois, USA).

\section{Results}

There were 164 orthotopic liver transplants between 1 January 2007 and 31 December 2009 at our center. Eighty-four patients were excluded ( $\triangleright$ Fig. $\mathbf{1}$ ). Of the remaining 80 patients, 49 recipients underwent both pre- and post-transplant colonoscopy (Group PrePost), and 31 patients had a post-OLT colonoscopy only (Group Post). Groups PrePost and Post did not differ with regard to sex ( $63 \%$ vs. $65 \%$ male, respectively; $P=1)$. The groups had similar median age at post-transplant colonoscopy $(61[\mathrm{IQR}=10]$ vs. $58[\mathrm{IQR}=12]$ years $)$, although the age distribution was different $(P<0.001)$. Characteristics of included patients are listed in $>$ Table $\mathbf{1}$.

\section{Pre-transplant findings}

Colorectal polyps were found in $37 \%(n=18)$ of patients and in $47 \%$ of patients over 50 years. Polyps were hyperplastic in $44 \%$ 


\section{All liver transplant recipients $(n=164)$}

\section{Excluded $(\mathbf{n}=\mathbf{8 4})$}

Previous OLT before $2007(n=2)$

OLT done outside of our center $(n=1)$

Total proctocolectomy $(n=1)$

Only post-OLT flexible sigmoidoscopy $(\mathrm{n}=9)$

No post-OLT colonoscopy $(n=71)$

- Died before post-OLT colonoscopy $(n=29)$

- Aged $<50$ at time of post-OLT colonoscopy planning $(n=18)$

- Refusal or absent at appointment $(n=10)$

- Lost at follow-up $(n=4)$

- Report unavailable $(\mathrm{n}=1)$

- Unknown (n=9)

\begin{tabular}{|c|c|}
\hline \multicolumn{2}{|c|}{ Included $(n=80)$} \\
\hline$\sqrt{ }$ & $\downarrow$ \\
\hline Group PrePost $(n=49)$ & $\begin{array}{l}\text { Group Post }(\mathbf{n}=\mathbf{3 1}) \\
\text { Reason for lack of } \\
\text { pre-OLT colonoscopy: } \\
\text { - Aged }<50 \text { at } \\
\text { transplant }(n=8) \\
\text { - Fulminant hepatitis } \\
(n=3) \\
\text { - Barium enema }(n=1) \\
\text { - No report available } \\
(n=19)\end{array}$ \\
\hline
\end{tabular}

- Fig. 1 Flow diagram for all liver transplant recipients. OLT, orthotopic liver transplant; Post, group with only post-transplant colonoscopy; PrePost, group with both pre- and post-transplant colonoscopies.

of patients and adenomas in $22 \%$ ( $\triangleright$ Table 2 ). A villous adenoma with high grade dysplasia was diagnosed in a 43-year-old patient with Crohn's disease, who underwent subsequent subtotal colectomy before transplant.

\section{Post-transplant findings}

The prevalence of polyps was $33 \%(n=26)$ overall and $37 \%$ in patients over 50 years. The prevalence of polyps did not differ in patients with and without pre-transplant colonoscopy (33\% vs. $32 \% ; P=1)$. The histological findings were adenomas in $62 \%$ of patients and hyperplastic polyps in $12 \%$ ( $\downarrow$ Table 2 ). Advanced or cancerous lesions were present in $5 \%$ of patients ( $15 \%$ of all lesions). The proportion of advanced adenomas and adenocarcinomas combined tended to be higher in Group Post ( $40 \%$ vs. $6 \%$ in Group PrePost; $P=0.055$ ). The proportion of $\geq 1 \mathrm{~cm}$ polyps tended to be greater in Group Post (30\% versus $6 \%$ in Group PrePost; $P=0.26$ ). A single 60 -year-old woman, screened before transplant at age 53, had a serrated polyp. One female, aged 50 at transplant and with no known CRC risk factors, did not undergo pre-transplant colonoscopy and was diagnosed with ade-
- Table 1 Characteristics of the 80 liver transplant recipients included in this study.

\begin{tabular}{|c|c|}
\hline Male, n (\%) & $51(64)$ \\
\hline White ethnicity, n (\%) & $74(93)$ \\
\hline \multicolumn{2}{|l|}{ Age, median [IQR], years } \\
\hline - At transplant & $57[10]$ \\
\hline - At post-transplant colonoscopy & $60[11]$ \\
\hline \multicolumn{2}{|l|}{ Median [IQR] years between: } \\
\hline - Pre-OLT colonoscopy and OLT & $0.5[0.8]$ \\
\hline - OLT and post-OLT colonoscopy & $5.5[1.8]$ \\
\hline Active/past smoking, $\mathrm{n}(\%)$ & $39(49)$ \\
\hline \multicolumn{2}{|l|}{ Liver disease before transplant, $\mathrm{n}(\%)^{1}$} \\
\hline - Hepatitis B & $9(11)$ \\
\hline - Hepatitis C & $15(19)$ \\
\hline - Alcoholic liver disease & $23(29)$ \\
\hline - NAFLD & $8(10)$ \\
\hline - PSC & $11(14)$ \\
\hline - Concomitant PSC and IBD & $9(11)$ \\
\hline - $\mathrm{PBC}$ & $13(16)$ \\
\hline - AlH & $8(10)$ \\
\hline - Cryptogenic or other & $7(9)$ \\
\hline \multicolumn{2}{|c|}{ Indication for post-transplant colonoscopy, n (\%) } \\
\hline - Screening & $44(55)$ \\
\hline - Surveillance & $11(14)$ \\
\hline - Diagnostic & $25(31)$ \\
\hline CNI-containing regimen, $\mathrm{n}(\%)$ & $59(74)$ \\
\hline \multicolumn{2}{|c|}{$\begin{array}{l}\text { AlH, autoimmune hepatitis; CNI, calcineurin inhibitor; IBD, inflammatory } \\
\text { bowel disease; IQR, interquartile range; NAFLD, nonalcoholic fatty liver dis- } \\
\text { ease; OLT, orthotopic liver transplant; PBC, primary biliary cirrhosis; PSC, } \\
\text { primary sclerosing cholangitis. } \\
{ }^{1} \text { For each case of transplant, there could be more than one liver disease. }\end{array}$} \\
\hline
\end{tabular}

nocarcinoma in situ 1.5 years post-OLT. Two patients developed anal squamous cell carcinomas in association with HPV at 3 and 8 years, respectively; the former was also diagnosed with a rectal neuroendocrine tumor 4.3 years post-OLT. Amongst the PSC/IBD patients $(n=11)$, only one developed a polyp.

\section{Predictors of post-transplant colorectal polyps}

Male sex and alcoholic liver disease were significantly associated with post-OLT polyps. These were also diagnosed more often in colonoscopies done for screening purposes than for other indications ( $>$ Table 3 ). In the logistic regression analysis, only two variables remained significant and were included in the model: alcoholic liver disease and indication of post-transplant colonoscopy. The odds of finding a polyp were 11 times greater in patients with alcoholic liver disease compared to those without (OR 11.3, 95\%Cl 3.2-39.4; $P<0.001)$. Screening colonos- 
- Table 2 Prevalence and histology of polyps and cancerous lesions before and after liver transplant.

\begin{tabular}{|c|c|c|}
\hline & $\begin{array}{l}\text { Pre-trans- } \\
\text { plant } \\
\left(\mathrm{n}=49^{1}\right)\end{array}$ & $\begin{array}{l}\text { Post- } \\
\text { transplant } \\
(n=80)\end{array}$ \\
\hline Patients with polyps, n (\%) & $18(37)$ & $26(33)$ \\
\hline $\begin{array}{l}\text { Patients aged } \geq 50 \text { years }{ }^{2} \text {, with polyps, } \\
n(\%)\end{array}$ & $17 / 36(47)$ & $26 / 70(37)$ \\
\hline Patients with $\geq 3$ polyps, $\mathrm{n}(\%)$ & $5(28)$ & $2(7)$ \\
\hline Polyps proximal to splenic flexure, n (\%) & $9(50)$ & $12(46)$ \\
\hline $\begin{array}{l}\text { Polyps found on screening colonoscopy, } \\
\mathrm{n}(\%)\end{array}$ & $6(33)$ & $19(73)$ \\
\hline Size $\geq 10 \mathrm{~mm}, \mathrm{n}(\%)$ & $1(6)$ & $4(15)$ \\
\hline \multicolumn{3}{|l|}{ Histology, n (\%) } \\
\hline - Hyperplastic polyp & $8(44)$ & $3(12)$ \\
\hline - Adenoma & $4(22)$ & $16(62)$ \\
\hline Tubular & 2 & 13 \\
\hline Tubulovillous (HGD) & 0 & $2(1)$ \\
\hline Villous (HGD) & $2(1)$ & 0 \\
\hline Sessile serrated & 0 & 1 \\
\hline - Inflammatory polyp & 0 & $1(4)$ \\
\hline - Colorectal cancer & 0 & $1(4)$ \\
\hline - Unavailable & $6(33)$ & $5(19)$ \\
\hline Advanced adenoma or cancer, n (\%) & $2(11)$ & $4(15)$ \\
\hline \multicolumn{3}{|c|}{$\begin{array}{l}\text { HGD, high grade dysplasia. } \\
149 / 80 \text { patients had a pre-transplant colonoscopy. } \\
{ }^{2} \text { At time of colonoscopy. }\end{array}$} \\
\hline
\end{tabular}

copies, compared to surveillance/diagnostic colonoscopies, were associated with post-transplant polyps (OR $5.1,95 \% \mathrm{Cl}$ $1.4-17.9 ; P=0.01)$. The other variables tested did not predict post-transplant colorectal polyps.

\section{Discussion}

Our findings demonstrate that there is presence of colorectal polyps in $37 \%$ of liver transplant patients before OLT and 33\% afterwards. A high proportion of post-transplant lesions were advanced adenomas or cancerous. The key finding of this study is that alcoholic liver disease was a strong predictor of posttransplant colorectal polyps.

Our data is in agreement with previous pre-OLT studies, one of which reported the presence of polyps in $42 \%$ of patients [9]. The single other study on post-liver transplant polyps found a similar prevalence of $29 \%$ [19]. Furthermore, Rudraraju and colleagues reported that $7.3 \%$ of their cohort of OLT recipients had advanced adenomas or cancerous lesions, similar to our findings [20].

The role of immunosuppression in the development of colorectal polyps possibly stems from reduced tumor immunosurveillance by the innate and adaptive immunity [21]. Reactivation of pro-oncogenic viruses, notably Epstein-Barr virus and $\mathrm{JC}$ virus, may contribute to an acceleration of the adenoma-carcinoma sequence $[22,23]$. Human papillomavirus reactivation is also a well-known risk factor for anal squamous cell carcinoma in organ transplant recipients [24].

To our knowledge, this study is the first to demonstrate that alcoholic liver disease strongly predicts colorectal polyp occurrence in liver transplant recipients. There have been multiple retrospective studies linking alcoholic liver disease to pre-transplant adenomas [25], as well as to de novo malignancies post-

- Table 3 Characteristics of patients with and without post-transplant polyps.

\begin{tabular}{|c|c|c|c|c|}
\hline & \multirow[t]{2}{*}{ All $(n=80)$} & \multicolumn{2}{|c|}{ Post-transplant polyps } & \multirow[t]{2}{*}{$P$ value } \\
\hline & & Present $(n=26)$ & Absent $(n=54)$ & \\
\hline Male, \% & 63.7 & 80.8 & 55.6 & 0.05 \\
\hline$\geq 60$ years old, $\%$ & 53.8 & 65.4 & 48.1 & 0.16 \\
\hline Current/past smoking, \% & 48.8 & 61.5 & 42.6 & 0.15 \\
\hline History of alcoholic liver disease, \% & 28.7 & 57.7 & 14.8 & $<0.001$ \\
\hline History of NAFLD, \% & 80.0 & 11.5 & 13.0 & 1.00 \\
\hline History of IBD/PSC, \% & 13.8 & 3.8 & 18.5 & 0.09 \\
\hline CNI-containing regimen, \% & 73.8 & 73.1 & 74.1 & 1.00 \\
\hline Presence of pre-transplant polyps, \% & 22.5 & 19.2 & 24.1 & 0.78 \\
\hline No pre-transplant colonoscopy, \% & 38.8 & 38.5 & 38.9 & 1.00 \\
\hline \multicolumn{5}{|l|}{ Colonoscopy post-transplant, \% } \\
\hline - Done $\geq 5$ years post-transplant & 50.0 & 46.2 & 51.9 & 0.81 \\
\hline - Done for screening purposes & 55.0 & 73.1 & 46.3 & 0.03 \\
\hline
\end{tabular}


OLT [26]. However, specific data on post-transplant colorectal polyps or CRC are lacking. A single earlier study has described a similar, albeit weaker, association, without a logistic regression model [19]. In the general population, alcohol consumption has been associated with colorectal adenomas [27], advanced adenomas [28], and CRC [29]. A recent systematic review of human and animal studies explored the possible mechanisms underlying alcohol's potential role in CRC carcinogenesis [30], which include mucosal damage by acetaldehyde [31], disruption of epithelial tight junctions [32], induction of cell proliferation [33], and increased expression or polymorphism of enzymes, particularly of cytochrome P450 2E1 [34].

There was a strong association between colonoscopies done for screening purposes and post-transplant polyps in our study. Contrary to these findings, certain studies have reported a higher prevalence of adenomas, advanced adenomas, and colorectal cancer in surveillance and diagnostic colonoscopies [17, 18]. Nevertheless, Doubeni and colleagues showed that screening colonoscopies had a higher yield for CRC [35]. The fact that polyp prevalence was low in our diagnostic/surveillance colonoscopies may be driven by endoscopies done for low-yield indications, such as nonspecific gastrointestinal symptoms [18]. In addition, patients in the surveillance group have, by definition, already undergone polyp resection or have more frequent endoscopies done, which likely decreases the yield of the posttransplant colonoscopy. Colonoscopies with an unidentified indication may also have been misclassified as screening ones.

One of our study's strengths is that, although it was retrospective in design, it represents one of the few with an endoscopic follow-up of transplant recipients who underwent pretransplant colonoscopy. Also, despite the sample size, we were able to generate a statistically significant logistic regression model with strong predictors of our primary outcome, indicating the robustness of the associations. Furthermore, this is the first study to identify alcoholic liver disease as a predictor for polyps in OLT recipients with a logistic regression analysis.

Our study has several limitations. Due to its retrospective nature, some data is missing, including descriptions based on the Paris classification in endoscopy reports, as well as certain polyp pathology reports. Patients may have had a pre-transplant colonoscopy at another center without our knowledge, thus being misclassified in Group Post. Only 49\% of patients were included, which likely increases the risk of selection bias. However, the proportion is higher (65\%) when considering only the $>50$-year-old transplant survivors and is also higher than in another similar study [19]. Due to sample size, logistic regression analyses were underpowered for certain variables. In addition, due to lack of reporting, possible important confounders, such as dietary habits, could not be accounted for in the subgroup analyses of alcoholic liver disease. Finally, given the distribution of liver diseases in our study population, most notably the high proportion of alcoholic liver disease, the results should be generalized to other liver transplant populations with caution.

In summary, patients with end-stage liver disease may be at high risk of colorectal polyps before and after liver transplant, and screening should be continued in both contexts, although the frequency of endoscopic examination remains unknown after transplant. In our study, alcoholic liver disease strongly predicted post-transplant polyps, and patients with a history of alcoholic liver disease may possibly benefit from more intensive endoscopic surveillance. A larger prospective cohort study of OLT recipients is needed to better characterize the incidence and natural history of colorectal polyps, ultimately with the goal of developing adapted post-liver transplant screening recommendations.

\section{Acknowledgments}

The authors would like to acknowledge Nancy Presse, PhD, for her assistance in statistical analyses.

\section{Competing interests}

None

References

[1] Pruthi J, Medkiff K, Esrason K et al. Analysis of causes of death in liver transplant recipients who survived more than 3 years. Liver Transpl 2001; 7: 811-815

[2] Park $\mathrm{H}$, Hwang $\mathrm{S}$, Ahn $\mathrm{C}$ et al. De novo malignancies after liver transplantation: incidence comparison with the Korean cancer registry. Transplant Proc 2012; 44: 802-805

[3] Herrero J, Alegre F, Quiroga J et al. Usefulness of a program of neoplasia surveillance in liver transplantation. A preliminary report. Clin Transplant 2009; 23: $532-536$

[4] Martin HL, Chen JW, Koczwara B. Cancer in liver transplant recipients: Management and outcomes. Asia Pac J Clin Oncol 2013; 9: 257-264

[5] Chak E, Saab S. Risk factors and incidence of de novo malignancy in liver transplant recipients: a systematic review. Liver Int 2010; 30: $1247-1258$

[6] Johnson E, Leverson G, Pirsch J et al. A 30-year analysis of colorectal adenocarcinoma in transplant recipients and proposal for altered screening. J Gastrointest Surg 2007; 11: 272-279

[7] Buell J, Papaconstantinou H, Skalow B et al. De novo colorectal cancer: five-year survival is markedly lower in transplant recipients compared with the general population. Transplant Proc 2005; 37: 960 - 961

[8] Leslie A, Carey F, Pratt $\mathrm{N}$ et al. The colorectal adenoma-carcinoma sequence. Br J Surg 2002; 89: 845-860

[9] Bhatt B, Lukose T, Siegel A et al. Increased risk of colorectal polyps in patients with non-alcoholic fatty liver disease undergoing liver transplant evaluation. J Gastrointest Oncol 2015; 6: 459-468

[10] Zaman A, Hapke R, Flora K et al. Prevalence of upper and lower gastrointestinal tract findings in liver transplant candidates undergoing screening endoscopic evaluation. Am J Gastroenterol 1999; 94: 895899

[11] Lucey M, Terrault N, Ojo L et al. Long-term management of the successful adult liver transplant: 2012 practice guideline by the American Association for the Study of Liver Diseases and the American Society of Transplantation. Liver Transpl 2013; 19: 3-26

[12] European Association for the Study of the Liver. EASL Clinical Practice Guidelines: Liver transplantation. J Hepatol 2016; 64: 433-485

[13] Singh S, Edakkanambeth Varayil ], Loftus E et al. Incidence of colorectal cancer after liver transplantation for primary sclerosing cholangi- 
tis: a systematic review and meta-analysis. Liver Transpl 2013; 19: $1361-1369$

[14] Sint Nicolaas J, de Jonge V, Steyerberg E et al. Risk of colorectal carcinoma in post-liver transplant patients: a systematic review and metaanalysis. Am J Transplant 2010; 10: 868 -876

[15] Singal AG, Gupta S, Lee J et al. Importance of determining indication for colonoscopy: implications for practice and policy. Clin Gastroenterol Hepatol 2014; 12: 1958-1963.e1-3

[16] Cotton P, Williams C, Hawes R et al. Practical gastrointestinal endoscopy: the fundamentals. Wiley; 2011

[17] Anderson JC, Butterly LF, Goodrich M et al. Differences in detection rates of adenomas and serrated polyps in screening versus surveillance colonoscopies, based on the new hampshire colonoscopy registry. Clin Gastroenterol Hepatol 2013; 11: 1308-1312

[18] Lieberman D, de Garmo P, Fleischer D et al. Colonic neoplasia in patients with nonspecific GI symptoms. Gastrointest Endosc 2000; 51: $647-651$

[19] Albright ], Bonatti H, Stauffer ] et al. Colorectal and anal neoplasms following liver transplantation. Colorectal Dis 2010; 12: 657-666

[20] Rudraraju M, Osowo A, Singh V et al. Do patients need more frequent colonoscopic surveillance after liver transplantation? Transplant Proc 2008; 40: 1522 - 1524

[21] Dunn GP, Bruce AT, Ikeda $\mathrm{H}$ et al. Cancer immunoediting: from immunosurveillance to tumor escape. Nat Immunol 2002; 3: 991 - 998

[22] Selgrad M, Koornstra J, Fini L et al. JC virus infection in colorectal neoplasia that develops after liver transplantation. Clin Cancer Res 2008; 14: $6717-6721$

[23] Park ], Choi M, Kim S et al. Increased incidence of colorectal malignancies in renal transplant recipients: a case control study. Am J Transplant 2010; 10: $2043-2050$

[24] Kwak E, Julian K. Human papillomavirus infection in solid organ transplant recipients. Am J Transplant 2009; 9: S151 - S160

[25] Jeschek P, Ferlitsch A, Salzl P et al. A greater proportion of liver transplant candidates have colorectal neoplasia than in the healthy screening population. Clin Gastroenterol Hepatol 2015; 13: 956 - 962
[26] Zhou J, Hu Z, Zhang Q et al. Spectrum of de novo cancers and predictors in liver transplantation: analysis of the Scientific Registry of Transplant Recipients Database. PLoS ONE 2016; 11: e0155179

[27] Ben Q, Wang L, Liu J et al. Alcohol drinking and the risk of colorectal adenoma: a dose-response meta-analysis. Eur J Cancer Prev 2015; 24 : $286-295$

[28] Bardou M, Montembault S, Giraud V et al. Excessive alcohol consumption favours high risk polyp or colorectal cancer occurrence among patients with adenomas: a case control study. Gut 2002; 50 : $38-42$

[29] Lieberman D, Prindiville S, Weiss D et al. Risk factors for advanced colonic neoplasia and hyperplastic polyps in asymptomatic individuals. JAMA 2003; 290: 2959-2967

[30] Oyesanmi O, Snyder D, Sullivan $\mathrm{N}$ et al. Alcohol consumption and cancer risk: understanding possible causal mechanisms for breast and colorectal cancers. Evid Rep Technol Assess (Full Rep) 2010: 1-151

[31] Pronko P, Bardina L, Satanovskaya V et al. Effect of chronic alcohol consumption on the ethanol- and acetaldehyde-metabolizing systems in the rat gastrointestinal tract. Alcohol Alcohol 2002; 37: 229 235

[32] Basuroy S, Sheth P, Mansbach C et al. Acetaldehyde disrupts tight junctions and adherens junctions in human colonic mucosa: protection by EGF and L-glutamine. Am J Physiol Gastrointest Liver Physiol 2005; 289: G367-G375

[33] Simanowski U, Suter P, Russell R et al. Enhancement of ethanol induced rectal mucosal hyper regeneration with age in F344 rats. Gut 1994; 35: $1102-1106$

[34] Morita M, Tabata S, Tajima O et al. Genetic polymorphisms of CYP2E1 and risk of colorectal adenomas in the Self Defense Forces Health Study. Cancer Epidemiol Biomarkers Prev 2008; 17: 1800 - 1807

[35] Doubeni C, Weinmann S, Adams K et al. Screening colonoscopy and risk for incident late-stage colorectal cancer diagnosis in average-risk adults: a nested case-control study. Ann Intern Med 2013; 158: 312 320 